\section{Journal homepage:http://www.journalijar.com Journal DOI:10.21474/IJAR01}

\section{RESEARCH ARTICLE}

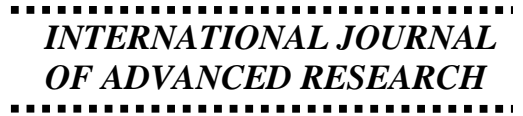

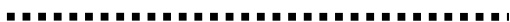

\title{
Formulation Development and Evaluation of Tadalafil Transdermal Patches Using Various Penetration Enhancers.
}

\author{
Mohammad Faizan ${ }^{1}$ andShikhaBaghel Chauhan ${ }^{2}$. \\ 1. Research Scholar, Amity Institute of Pharmacy, Amity University, Noida, Uttar Pradesh, India. \\ 2. Assistant Professor, Amity Institute of Pharmacy, Amity University, Noida, Uttar Pradesh, India.
}

\section{Manuscript Info}

\section{Manuscript History:}

Received: 22 May 2016

Final Accepted: 19 June 2016

Published Online: July 2016

Key words:

Transdermal patch, Tadalafil,

Penetration Enhancers, Chitosan, In

vitro permeation studies

*Corresponding Author

Ms. Shikha Baghel

Chauhan

\section{Abstract}

The aim of this research study was to develop transdermal Patch of tadalafil using various skin penetration enhancers in different concentrations like Eugenol, 1- Octanol,DMSO and Peppermint oilfor erectile dysfunction and to understand the role of penetration enhancer on the drug delivery in transdermal patch. The physicochemical compatibility and preformulation studies of the drug and the polymers was studied by Infrared spectroscopy and HPLC. Different formulation of transdermal patches using Chitosan $4 \%$ w/w as polymer and polyethylene glycol 400 and glycerol (1:1) as plasticizerwere fabricated.The results suggested no physicochemical incompatibility between the drug and the polymers. Formulated patches were evaluated for folding endurance, thickness, weight uniformity, percentage moisture content, percentage moisture uptake, content uniformity in-vitro permeation studies and in-vitro drug release were performed in 50\% v/vethanolic phosphate buffer of $\mathrm{pH}$ 7.4. The result showed that formulation DMSO-5 found to be best formulation, as it permeated $59.42 \%$ drug through rat Dorsal skin as compare of control patch. Overall results of all permeation enhancers stated that DMSO was found to be the best penetration enhancer, as it has the best penetration ability for tadalafil transdermal drug delivery.

\section{Introduction:-}

Copy Right, IJAR, 2016,. All rights reserved.

A recent approach to drug delivery is to deliver the drug into systemic circulation at predetermined rate using skin as a site of application. Transdermal patches deliveredthe drug through the skin in controlled and predetermined manner in order to increase the therapeutic efficacy of drug and reduced side effect of drug. TDDS has gained a lot of interest during the last decade as it offers many advantages over the conventional dosage forms and oral controlled release delivery systems notably avoidance of hepatic first pass metabolism, less frequency of administration, reduction in gastrointestinal side effects and improves patient compliance ${ }^{1,5}$. Transdermal therapeutic systems are defined as a self-contained, discrete dosage forms which, when applied to the intact skin, deliver the drug, through the skin at control rate to the systemic circulation. Transdermal formulation maintain drug concentration within the therapeutic window for prolong period of time ensuring that drug levels neither fall below the minimum effective concentration nor exceed the maximum effective concentration. To date many chemical and physical approacheshave been applied to increase the efficacy of the material transfer across the intact skin, by use of the penetration enhancers, enhancers, Iontophoresis, Sonophoresis and the use of colloidal carriers such aslipid vesicles (liposomes and Proliposomes) and non-ionic surfactant vesicles like niosomes and proniosomes ${ }^{2}$.

Tadalafil is used in the treatment of erectile dysfunction, and is a potent, reversible, competitive inhibitor of phosphodiesterase 5 (PDE5), an enzyme that inactivates cyclic guanosine monophosphate (cGMP). Inhibition of PDE5 in the corpus cavernosum of the penis increases intracellular cGMP levels, thereby facilitating relaxation of smooth muscle leading to penile erection.94\% of tadalafil in plasma is protein bound. Tadalafil clearance is 
predominately via hepatic metabolism by CYP3A to a catechol that undergoes methylation and is extensively conjugated to form the major circulating metabolite, a methylcatechol glucuronide ${ }^{3}$ (a minor amount of the unconjugated metabolite is also detected in plasma).

Tadalafil was chosen as the model candidate for this study since it possesses near ideal characteristics that a drug must have in formulating a transdermal drug delivery system: low molecular weight, a favourable logarithmic partition coefficient, smaller dose range. It also means multiple daily administrations with subsequent lack of patient compliance. The aim of the present investigation was to develop and evaluate transdermal patches of Tadalafil to provide drug at a controlled-release rate with a goal of reducing the frequency of oral administration for effective treatment erectile dysfunction.

\section{Materials and Methods:-}

Tadalafil was obtained as a gift samples from Ranbaxy laboratories Gurgaon Haryana. Chitosan was purchased from HiMedia Laboratories Mumbai. Eugenol, DMSO, 1-Octanol, and Lactic acid were purchased from CDH laboratories New Delhi. PEG 400 and Glycerol were purchased from Finar limited, Ahmedabad. All other laboratory chemicals used in the study were of analytical reagents grade.

\section{Characterisation of pure drug:-}

\section{Solubility:-}

The solubility of drug was determined in Water (W), methanol (M), Ethanol (E), Chloroform(C), in different combination to find out best Solvent for TDDS.

\section{Partition coefficient determination:-}

The partition coefficient $(\log \mathrm{P})$ is a measurement of lipophilicity of molecules, which can be used to predict its capability to cross biological membrane. The Partition coefficient studies were performed using n-octanol as nonaqueous phase and water as aqueous phase. The two phases were mixed in equal quantities and kept for saturation with each other in separating funnel. After mixing the system remain undisturbed for half an hour. About $10 \mathrm{mg}$ of drug added to this solution and was shaken occasionally in separating funnel. After shaken the resulting solution was kept a site for 24 hour. After 24 hour two phases were separated in a separating funnel. The aqueous phase was filtered through whatmann filter paper, suitably diluted and amount of Tadalafil in aqueous phase was determined by measuring absorbance at $284 \mathrm{~nm}$ using UV spectrophotometer. The partition coefficient of Tadalafil was calculated from the ratio between the concentration of Tadalafil in organic and aqueous phases from the below mentioned formula ${ }^{4}$.

$$
\log P_{\text {oct } / \text { wat }}=\log \left(\frac{[\text { solute }]_{\text {octanol }}}{[\text { solute }]_{\text {water }}^{\text {un-ionized }}}\right)
$$

Melting point:-

Melting point of tadalafil was determined using Digital Melting point Apparatus which contain silicone oil and a lance through which we can see the proper Image of melted material. A small amount of tadalafil was taken in a capillary and inserted in to the chamber containing Silicone oil. Apparatus was switched on and temperature knob was set. As temperature was raised, drug started to melt. Temperature at which drug melted was recorded. It was repeated three times to ensure Accuracy.

\section{UV Analysis of drug:-}

UV Analysis of Drug was carried out to find out the Maximum wavelength ( $\lambda$ max) of tadalafil. To find out wavelength, Stock Solution of tadalafil in Methanol was prepared. 10mg drug was weighed and transfer to measuring cylinder containing $10 \mathrm{ml}$ methanol. Further dilutions of required concentration were made using following equation ${ }^{4,12}$.

$$
\mathrm{C}_{1} \mathrm{~V}_{1=} \mathrm{C}_{2} \mathrm{~V}_{2}
$$

Where $\mathrm{C}_{1=}$ concentration of Known solution i.e. Stock solution

$\mathrm{C}_{2}=$ concentration of Unknown solution i.e. required Solution

$\mathrm{V}_{1=}$ Volume of Known Solution

$\mathrm{V}_{2=}$ Volume of Unknown Solution 


\section{Interaction studies:-}

Interaction studies were performed to check whether drug or excipients are interacting or not. To find out any interaction drug and other excipients were taken in appropriate amount and kept in a dish under specified condition at room temperature.

Tadalafil with polymer i.e. Chitosan was kept at room temperature in a dish in a specified amount and likely other excipient were also kept in other dishes with drug. FT-IR was done to check the interaction between drug and excipients.

\section{HPLC analysis ${ }^{7}:-$}

Preparation of Mobile phase ${ }^{8}:-$

A quantity sufficient to make one litre of phosphate buffer $\mathrm{pH}$ 7. The $\mathrm{pH}$ was adjusted by using $0.1 \mathrm{nN} \mathrm{NaOH}$. The buffer was filtered by using $0.22 \mu \mathrm{m}$ membrane filter followed by ultra-sonication for 20 minutes (MOBILE PHASE A). And HPLC grade acetonitrile filtered by using $0.22 \mu \mathrm{m}$ membrane filter was used as (MOBILE PHASE B).

\section{Stock Solution:-}

Stock solutions of Tadalafil were prepared by using HPLC grade methanol at a concentration of $1 \mathrm{mg} / \mathrm{ml}$ followed by vortex mixing.

\section{Solutions of Standards:-}

The solutions at concentration of $50,100,200,400,500 \mu \mathrm{g} / \mathrm{mL}$, were also prepared by diluting stock solution of external standard Tadalafil in methanol for constructing standard curve. All these samples were mixed well and filtered through $0.22 \mu \mathrm{m}$ syringe filter before injecting into column at a flow rate of $0.8 \mathrm{ml} / \mathrm{min}$.

\section{Standard calibration curve:-}

Standard calibration curve of tadalafil was prepared using 50\% ethanolic phosphate buffer saline solution. Weighed amount of drug $10 \mathrm{mg}$ was added to $10 \mathrm{ml} 50 \%$ Ethanolic phosphate buffer saline. Further dilution was done with the help of same solvent. 2, 4, 6, $810,1214 \mathrm{mcg} / \mathrm{ml}$ concentration solution were prepared and absorption was taken at $284 \mathrm{~nm}$ in UV spectroscopy.

\section{Fabrication of Transdermal Patch:-}

Patches were prepared using solvent casting method as per Table 1 . The chitosan was weighed accurately as $4 \% \mathrm{w} / \mathrm{v}$ of total solution. $15 \% \mathrm{v} / \mathrm{vmethanolic}$ water was used as solvent. Beaker was kept on magnetic stirrer at moderate speed to obtain homogenous mixture. Chitosan was transferred to $20 \mathrm{ml}$ beaker and lactic Acid $50 \% \mathrm{w} / \mathrm{v}$ was used to solubilise the chitosan. PEG 400 and Glycerol (1:1) was used as plasticizer and transferred to beaker containing chitosan. Penetration enhancer was added and transferred to beaker. Solution was made up to $18 \mathrm{ml}$ with solvent and kept for 24 hours to obtain homogeneous mixture. After 24 hours $3 \mathrm{ml}$ solution was transferred to each Teflon mould and was kept at $40^{\circ} 0 \mathrm{C}$ overnight in oven. After 24 hours patches were scratched from mould and kept in desiccator until used.

Table: 1:-Compositionof different formulations containing Tadalafil

\begin{tabular}{|l|l|l|l|l|l|l|}
\hline $\begin{array}{l}\text { Ingredients } \\
\text { Formulations } \\
\downarrow\end{array}$ & $\begin{array}{l}\text { Tadalafil } \\
(\mathbf{m g})\end{array}$ & $\begin{array}{l}\text { Chitosan } \\
\mathbf{4 \%} \mathbf{w} / \mathbf{v} \\
(\mathbf{m g})\end{array}$ & $\begin{array}{l}\text { PEG:Glycerol } \\
\mathbf{2 0 \%} \mathbf{w} / \mathbf{v} \\
(\boldsymbol{\mu l})\end{array}$ & $\begin{array}{l}\text { Lactic } \\
\text { Acid } \\
\mathbf{5 0 \%} \mathbf{w} / \mathbf{v} \\
(\boldsymbol{\mu l})\end{array}$ & $\begin{array}{l}\text { Penetration } \\
\text { Enhancer } \\
\mathbf{\%} \mathbf{w} / \mathbf{v} \\
(\boldsymbol{\mu l})\end{array}$ & $\begin{array}{l}\mathbf{1 5 \%} \\
\text { Methanolic } \\
\text { Water } \\
(\mathbf{m l})\end{array}$ \\
\hline WPE & 16 & 72 & 12 & 40 & - & 3 \\
\hline EUG-5 & 16 & 72 & 12 & 40 & 4 & 3 \\
\hline EUG10 & 16 & 72 & 12 & 40 & 8 & 3 \\
\hline PEP-5 & 16 & 72 & 12 & 40 & 4 & 3 \\
\hline PEP-10 & 16 & 72 & 12 & 40 & 8 & 3 \\
\hline OCT-5 & 16 & 72 & 12 & 40 & 4 & 3 \\
\hline OCT-10 & 16 & 72 & 12 & 40 & 8 & 3 \\
\hline DMSO-5 & 16 & 72 & 12 & 40 & 4 & 3 \\
\hline DMSO-10 & 16 & 72 & 12 & 40 & 8 & 3 \\
\hline
\end{tabular}




\section{Evaluation of Patches:-}

The prepared transdermal patches were evaluated for their physicochemical characteristics such asaverage weight, folding endurance,Thickness, Percent moisture loss, Percent moisture absorption, drug content, in vitro drug release and in vitro drug permeation studies.

Folding Endurance:-

Folding endurance was calculated by repeatedly folding the film at the same place until it broke the no. of times the film could be folded at the same place without breaking was the folding endurance?

\section{Average weight:-}

Patches of each formulation were weighed individually. The average weight was calculated and percent deviation of each patch from average weight was determined.

\section{Thickness:-}

The thickness of each polymer film or patch was measured at three different points using vernier caliper and the average thickness was measured. The thickness of the patches was varied from 0.20 to $0.22 \mathrm{~mm}$.

\section{Percentage moisture absorption:-}

The patches were accurately weighed and kept in desiccator containing saturated solution of sodiumchloride whichmaintains $75 \% \mathrm{RH}$ at $25^{\circ} \mathrm{C}$. After 72 hours the patches were taken out from desiccator and weighed. The percentage moisture content was calculated by using following formula ${ }^{9}$.

Percentage moisture content $=($ final weight-initial weight/final weight $) \times 100$

\section{Percentage moisture loss determination:-}

The moisture loss studies provide information regarding the stability of the formulations. The prepared patches were weighed individually and kept in desiccators containing fused calcium chloride at room temperature for 72 hours. After 72 hours the patches were taken out and reweighed. The percentage moisture loss was calculated from the formula mentioned below

Percentage moisture content $=($ final weight-initial weight/final weight $) \times 100$

\section{Drug content uniformity of films:-}

Drug content of the prepared transdermal patch was determined ${ }^{6}$.Specified area of patch $\left(1 \mathrm{~cm}^{2}\right)$ was cut and added to a beaker containing 50\% v/vethanolic phosphate buffer $\mathrm{pH} 7.4$ in specific volume of $100 \mathrm{ml}$. Then the medium was stirred with magnetic beads. The content were filtered through a whatmann filter paper and filtrate was examined for the drug content against the reference solution consisting of placebo films (containing no drug) with the UV spectrophotometer (Perkin Elmer) at $\lambda \max 284 \mathrm{~nm}$, and average readings were recorded.

\section{Physical Appearance:-}

The polymer film was evaluated for their physical appearance and graded asopaque/transparent/smooth/wrinkled/dry flexible.

\section{In-vitro drug release study:-}

In-vitro drug release studies were performed by using a keshrayChien cell with a receptor compartment having capacity of $25 \mathrm{ml}$. dialysis membrane which is a semipermeable having various biomedical application were fabricated ${ }^{11}$.The dialysis membrane having a pore size $0.45 \mu$ was mounted between the donor and receptor compartment of the keshrayChien cell. The prepared transdermal patch was placed on the dialysis membrane and covered with aluminium foil. The receptor compartment of the diffusion cell was filled with 50\% ethanolicphosphate buffer $\mathrm{pH}$ 7.4. The whole assembly was fixed on a hot plate magnetic stirrer, and the solution in the receptor compartment was constantly and continuously stirred using magnetic beads and the temperature was maintained at $37 \pm 0.5^{\circ} \mathrm{C} .1 \mathrm{ml}$ sample was withdrawn at time interval of $2,4,6,8 \mathrm{hrs}$ and so on for 24 hours. Same amount of solvent was added to receptor compartment to maintain sink condition and analysed for drug content spectrophotometrically.

\section{In vitro skin permeation studies:-}


An abdominal skin of mice was used for the study ${ }^{10}$. Hair was removed and the area washed with distilled water. Mice were euthanized by cervical dislocation, abdominal skin was excised and the fatty material attached to the dermis was peeled off. The skin was kept in $50 \% \mathrm{v} / \mathrm{v}$ ethanolic phosphate buffer for overnight. Keshray-Chien type diffusion cell with $1.6 \mathrm{~cm}^{2}$ diameter was used for permeation studies. The receptor compartment contained $50 \% \mathrm{v} / \mathrm{v}$ ethanolicPBS ( $\mathrm{pH} \mathrm{7.4)} \mathrm{and} \mathrm{was} \mathrm{maintained} \mathrm{at} 37 \pm 0.5^{\circ} \mathrm{C}$ with stirring using a magnetic stirrer The transdermal patch of $2.0096 \mathrm{~cm}^{2}$ was placed on the skin and aluminium foil was placed over patch and donor compartment was attached with the help of springs. Samples of $1.0 \mathrm{ml}$ was withdrawn at time interval of 2, 4, 6, $8 \mathrm{hrs}$ and so on and replaced immediately with an equal volume of $50 \% \mathrm{v} / \mathrm{v}$ PBS. The permeation of drug in the presence and absence of penetration enhancers was compared. The absorbance of the sample was measured at $284 \mathrm{~nm}$. The percentage of drug permeated was calculated and plotted against time.

\section{Results:-}

Solubility:-

Tadalafil was found soluble in organic solvent as seen in Table 2. Tadalafil is found practically insoluble in water.

Table:- 2 Solubility profile of drug

\begin{tabular}{|l|l|}
\hline Solvent & Solubility \\
\hline Chloroform & +++ \\
\hline Methanol & +++ \\
\hline Ethanol & ++ \\
\hline Polyethylene Glycol & +++ \\
\hline Water & -- \\
\hline
\end{tabular}

Partition coefficient $(\log \mathbf{P})$ : it was found to be 2.36 .

Melting point: Melting point of tadalafil was found to be $293^{\circ} \mathrm{c}$.

UV Spectroscopy: scanning for $\lambda_{\max }$ ofTadalafil was done in methanol in the range of 400- $200 \mathrm{~nm}$.After scanning for over a range of 400-200 $\mathrm{nm}$ on a double beam UVSpectrophotometer, solution of Tadalafil of showed maximum absorbance at 284 .

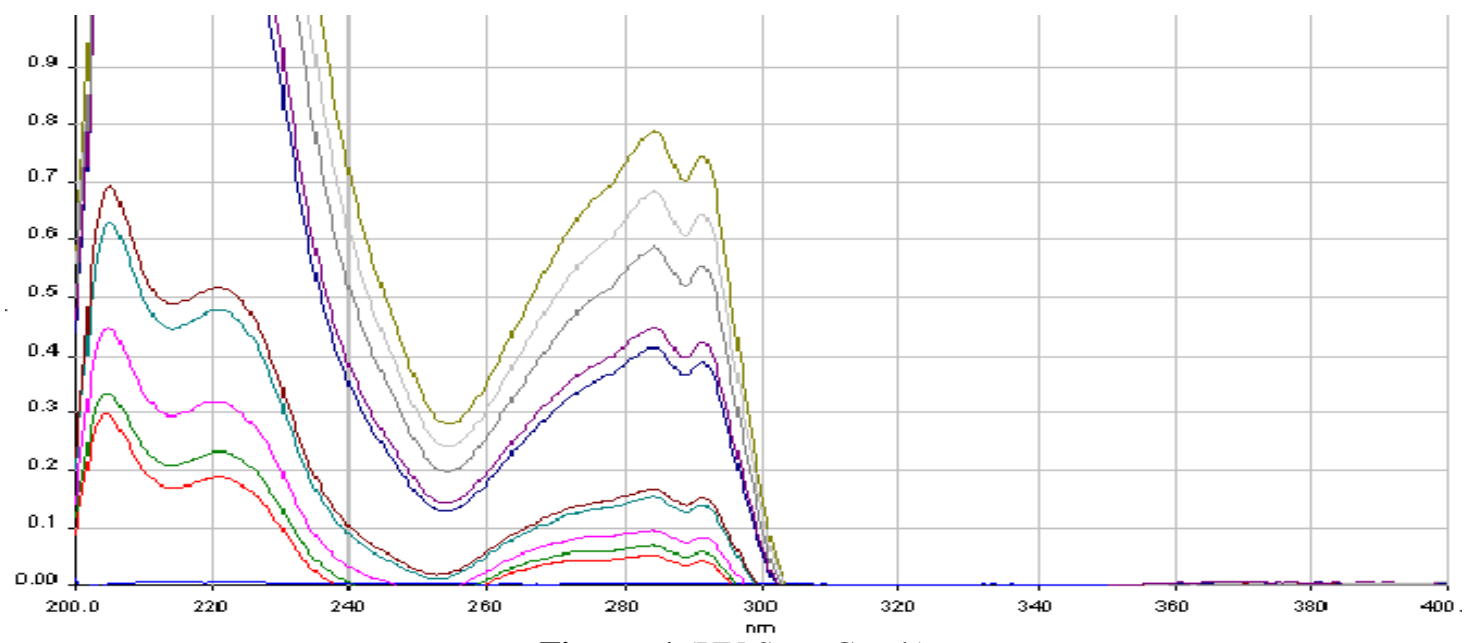

Figure: 1 (UV Scan Graph)

\section{HPLC Analysis of tadalafil:-}

HPLC Analysis of Tadalafil was done using Acetonitrile and Phosphate buffer $\mathrm{pH} 7$ as mobile phase in (60:40) ratio with $0.8 \mathrm{ml} / \mathrm{min}$ rate using C18 column. Graph of HPLC is given below. Retention time was found to be $6.37 \mathrm{~min}$ with a height of $619.34 \mathrm{mV}$. It was compared with standard spectra and found to be right. 


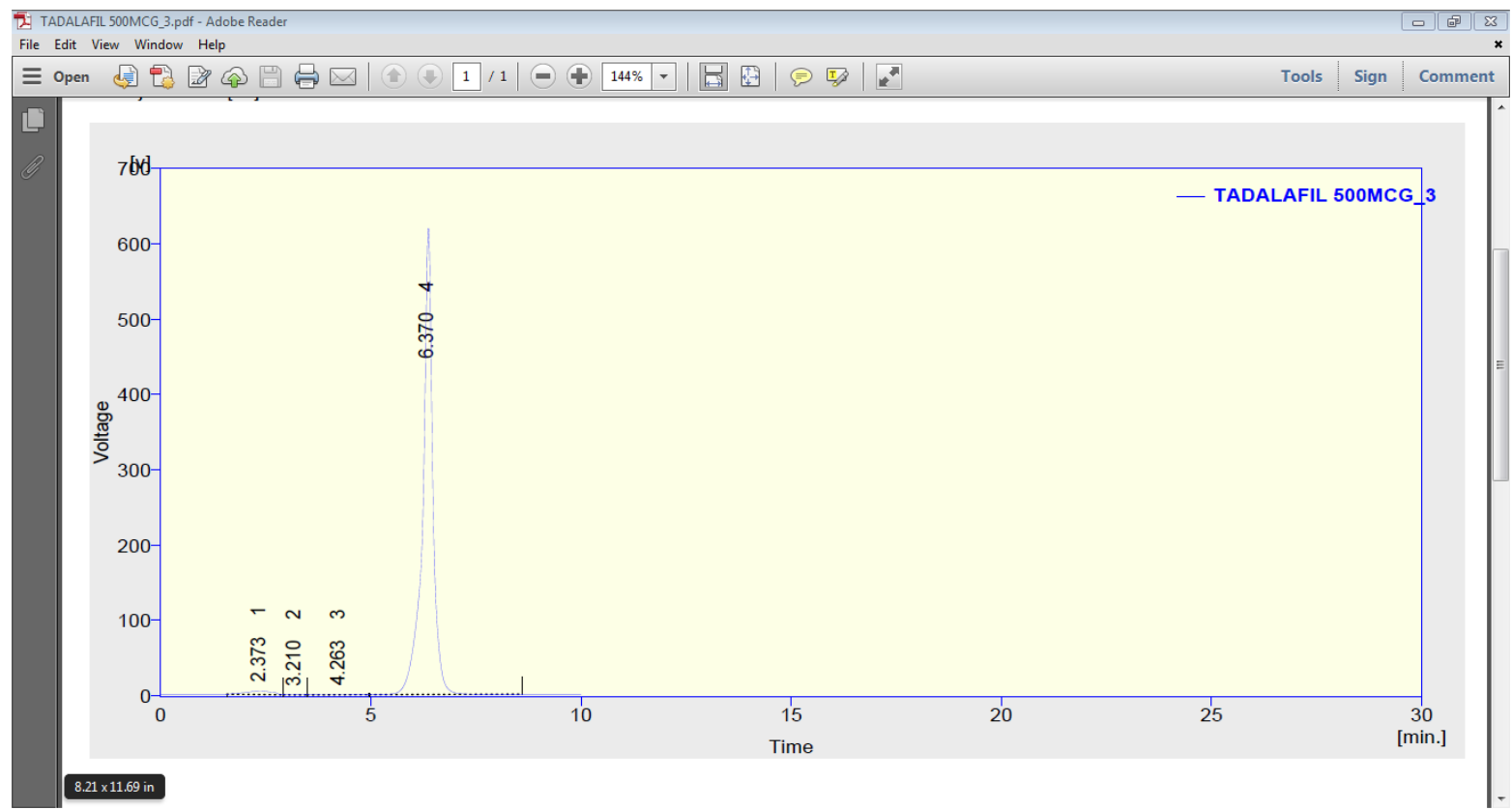

Figure:2 HPLC curve of tadalafil

\section{FT-IR analysis of Drug:-}

FT-IR spectra was got using $\mathrm{KBr}$ pellet technique. It was compared to standard spectra. Spectra found to be was good which indicated that tadalafil was pure. Spectra of medicated patch of tadalafil was also obtained by using same technique, it indicated there was no interaction between excipients and drug

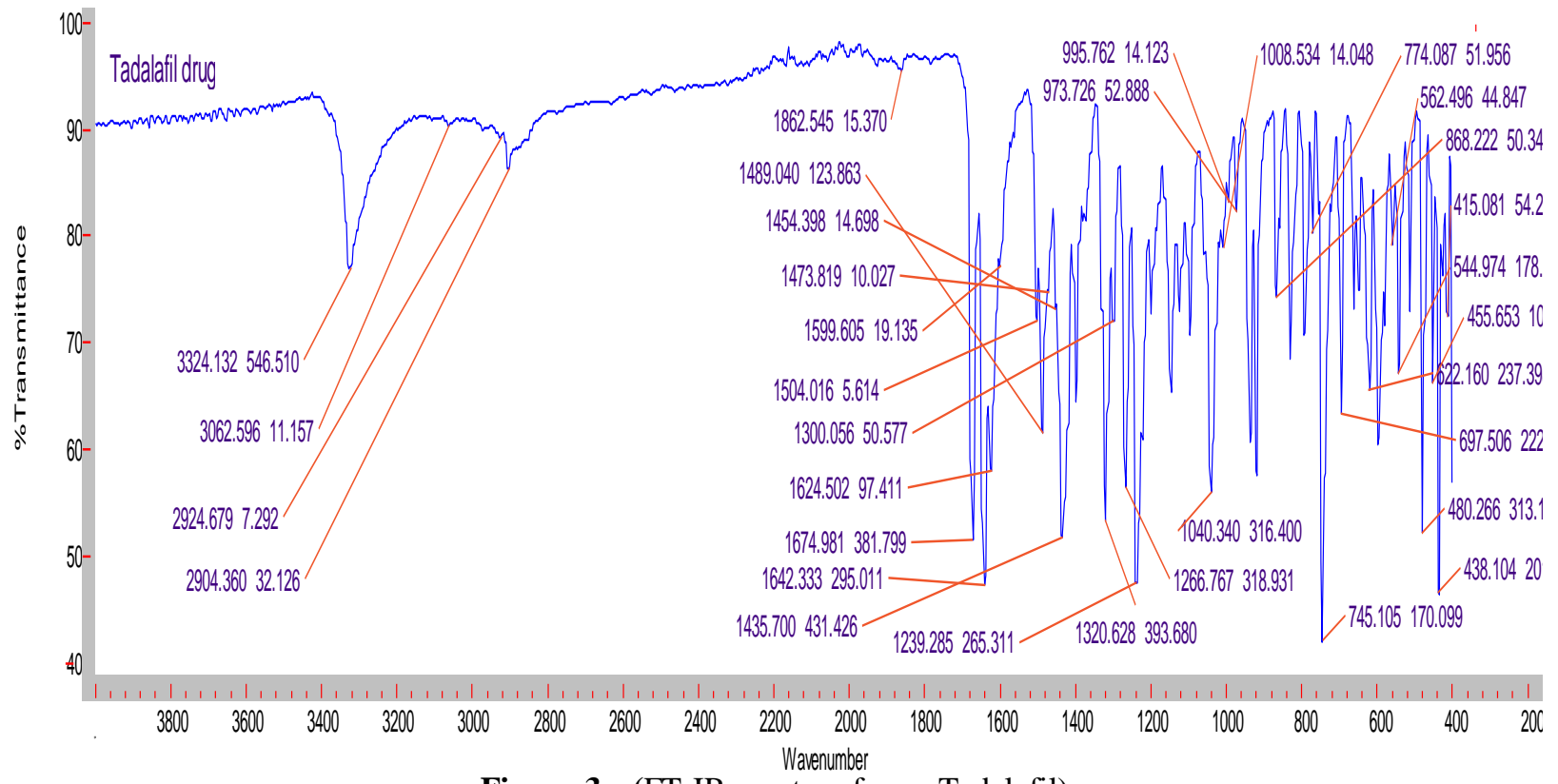

Figure:3:- (FT-IR spectra of pure Tadalafil) 


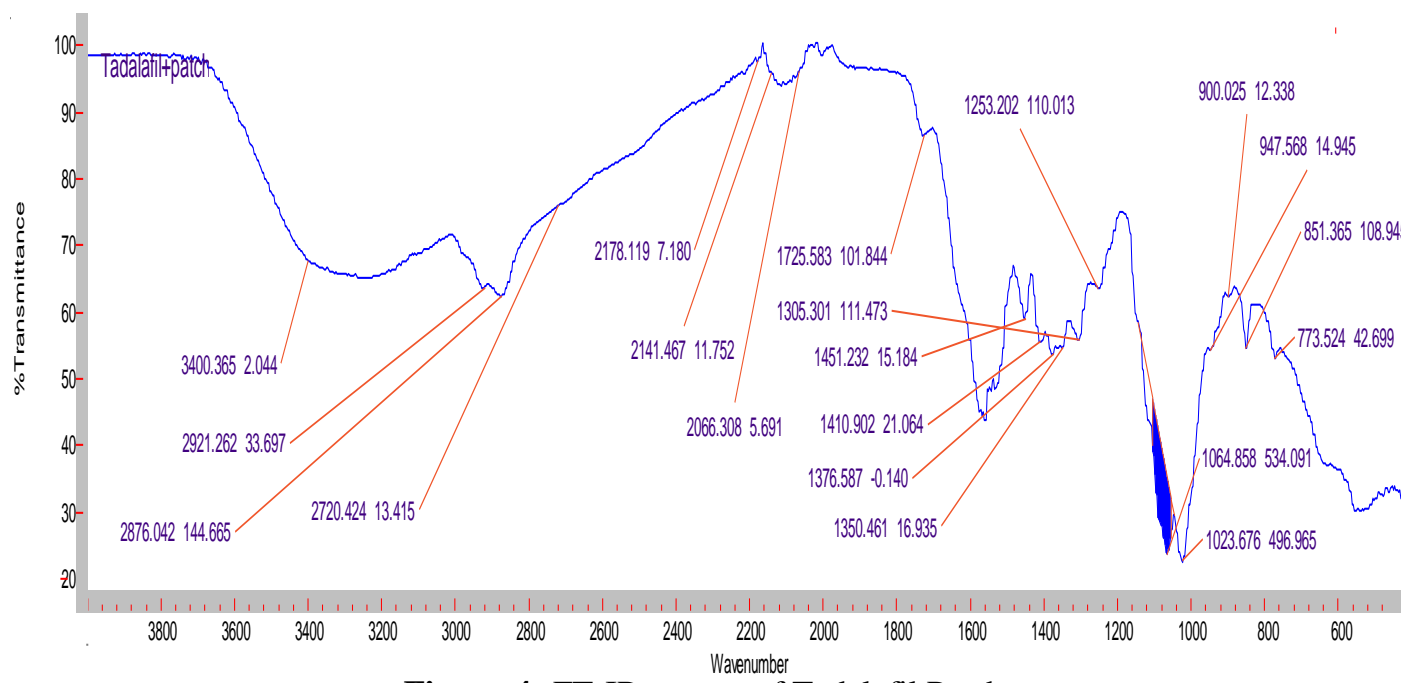

Figure:4:-FT-IR spectra of Tadalafil Patch

\section{Standard Calibration Curve of tadalafil:}

Table:3:-(Absorbance of standard drug at different concentration)

\begin{tabular}{|c|c|c|}
\hline Sr. No. & $\begin{array}{c}\text { Concentration } \\
\boldsymbol{\mu g} / \mathbf{m l}\end{array}$ & Absorbance \\
\hline 1 & 0 & 0000 \\
\hline 2 & 2 & 0.0602 \\
\hline 3 & 4 & 0.1309 \\
\hline 4 & 6 & 0.1976 \\
\hline 5 & 8 & 0.2677 \\
\hline 6 & 10 & 0.3446 \\
\hline 7 & 12 & 0.4014 \\
\hline 8 & 14 & 0.5042 \\
\hline
\end{tabular}

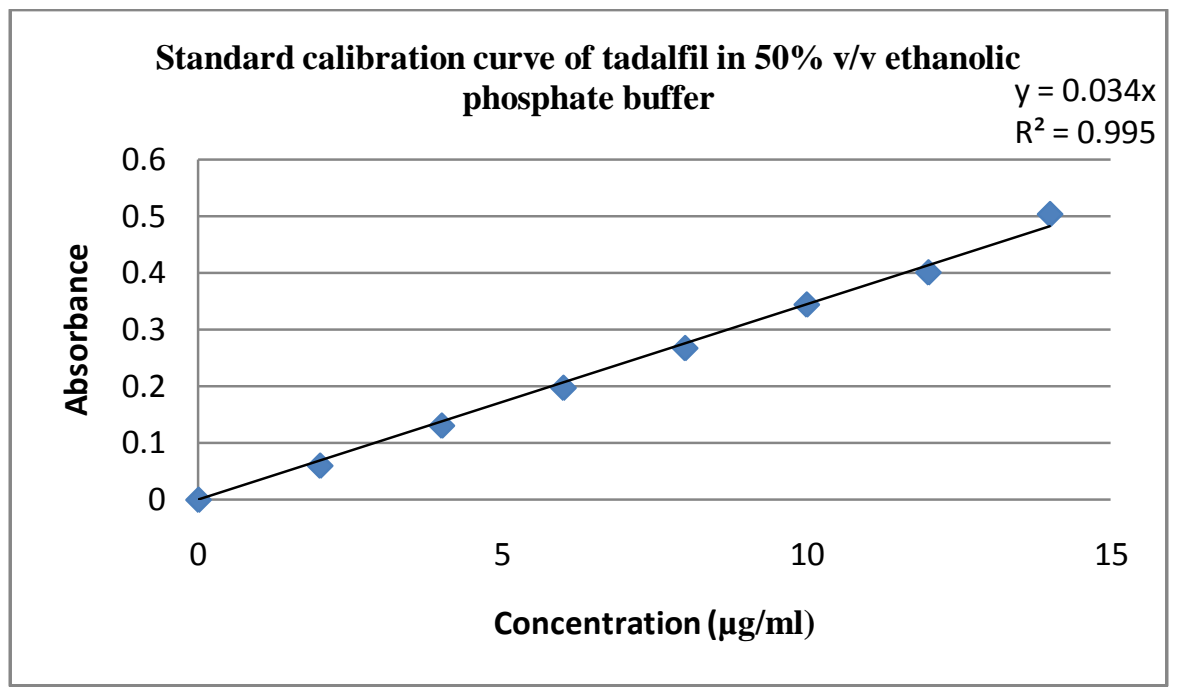

Figure: 5:- (standard calibration curve of drug) 


\section{In-vitro drug release study of Tadalafil:-}

In-vitro drug release study was performed using 50\% v/v ethanolic phosphate buffer as seen in Table 4..Assembly was kept at $37 \pm 0.5^{\circ} \mathrm{C}$ temperature. Samples were withdrawn at regular interval of 2 hours. Analysis of samples was done at $284 \mathrm{~nm}$ using double beam UV spectrophotometer. Drug was found to release up to 79.20\%.

Table: 4:-(Shows In vitro Drug Release studies of tadalafil patches)

\begin{tabular}{|l|l|l|l|l|l|l|l|l|l|l|}
\hline $\begin{array}{l}\text { Sr. } \\
\text { No }\end{array}$ & $\begin{array}{l}\text { Time } \\
\text { Hrs }\end{array}$ & \multicolumn{9}{|c|}{ Formulations } \\
\hline & & WPE & EUG-5 & EUG-10 & PEP-5 & PEP-10 & OCT-5 & OCT-10 & $\begin{array}{l}\text { DMSO- } \\
5\end{array}$ & $\begin{array}{l}\text { DMSO- } \\
10\end{array}$ \\
\hline 1 & 00 & 000 & 00 & 00 & 00 & 00 & 00 & 00 & 00 & 00 \\
\hline 2 & 2 & 15.52 & 13.26 & 11.69 & 13.36 & 9.32 & 12.36 & 8.12 & 12.32 & 10.35 \\
\hline 3 & 4 & 21.09 & 15.36 & 16.84 & 17.95 & 15.63 & 15.85 & 13.34 & 15.56 & 13.62 \\
\hline 4 & 6 & 30.89 & 19.69 & 17.65 & 19.64 & 18.93 & 17.52 & 17.23 & 19.38 & 17.65 \\
\hline 5 & 8 & 35.28 & 24.86 & 23.32 & 21.96 & 23.85 & 19.78 & 23.64 & 21.84 & 23.54 \\
\hline 6 & 10 & 43.12 & 29.54 & 27.94 & 24.96 & 28.65 & 24.54 & 27.58 & 27.61 & 24.78 \\
\hline 7 & 12 & 31.61 & 38.92 & 31.96 & 29.56 & 33.55 & 28.21 & 24.23 & 35.20 & 26.84 \\
\hline 8 & 14 & 47.51 & 43.45 & 33.00 & 34.93 & 37.54 & 33.84 & 35.52 & 31.50 & 33.23 \\
\hline 9 & 16 & 56.16 & 39.45 & 39.96 & 39.76 & 41.55 & 29.54 & 41.26 & 43.21 & 37.69 \\
\hline 10 & 18 & 64.64 & 48.63 & 46.39 & 49.82 & 47.73 & 39.35 & 46.57 & 49.18 & 45.67 \\
\hline 11 & 20 & $\mathbf{7 9 . 2 0}$ & 55.30 & 52.67 & 55.47 & 51.65 & 48.89 & 54.45 & 59.81 & 51.75 \\
\hline 12 & 22 & 73.19 & 58.88 & 59.78 & 63.71 & 58.64 & 57.38 & 61.86 & 67.21 & 58.85 \\
\hline 13 & 24 & 70.07 & 63.54 & 64.99 & 71.54 & 67.32 & 63.78 & 72.61 & 78.45 & 67.39 \\
\hline
\end{tabular}

Figure: 6:- (Shows cumulative drug release of drug vs time of tadalafilpatches)

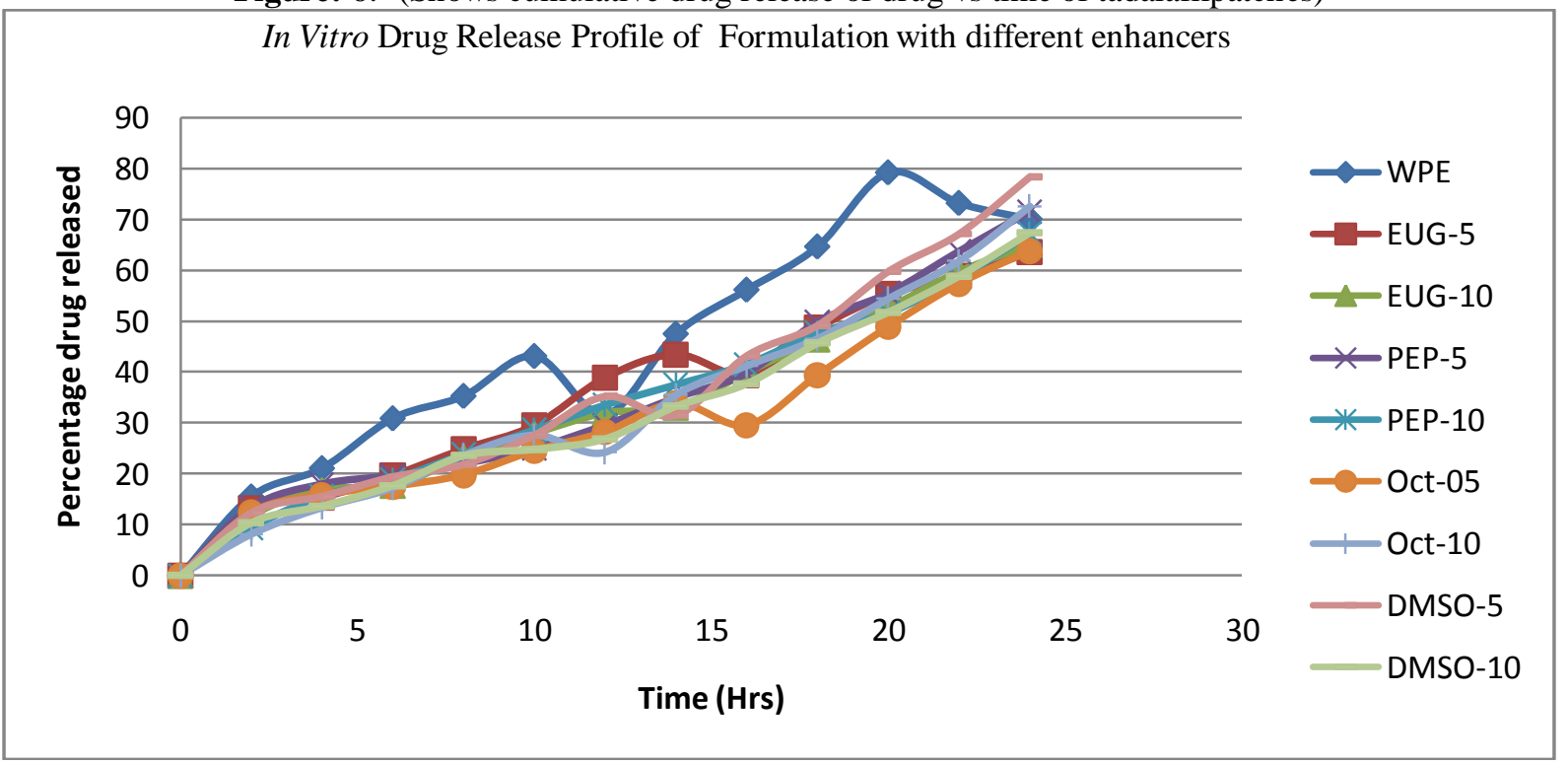




\section{Evaluation of Transdermal formulations}

\section{A) Physical evaluation of Transdermal formulations}

Table: 5 (Physical parameters of different formulations)

\begin{tabular}{|l|l|l|l|l|l|l|l|}
\hline $\begin{array}{l}\text { Parameters } \\
\text { Formulation } \\
\mathbb{N}\end{array}$ & $\begin{array}{l}\text { Folding } \\
\text { endurance }\end{array}$ & $\begin{array}{l}\text { Average } \\
\text { Weight } \\
(\mathbf{m g})\end{array}$ & $\begin{array}{l}\text { Thickness } \\
(\mathbf{m m})\end{array}$ & $\begin{array}{l}\text { Percentage } \\
\text { moisture } \\
\text { content }\end{array}$ & $\begin{array}{l}\text { Percentage } \\
\text { moisture } \\
\text { Absorbance }\end{array}$ & $\begin{array}{l}\text { Drug } \\
\text { content } \\
\text { uniformity }\end{array}$ & Transparency \\
\hline WPE & $415 \pm 10$ & $160.8 \pm 5$ & $0.20 \pm 0.001$ & $8.64 \pm 3$ & $11.11 \pm 5$ & $88 \pm 5$ & Moderate \\
\hline EUG-5 & $430 \pm 10$ & $158.6 \pm 4$ & $0.21 \pm 0.001$ & $7.59 \pm 5$ & $14.13 \pm 5$ & $85 \pm 5$ & Moderate \\
\hline EUG-10 & $410 \pm 10$ & $160 \pm 5$ & $0.21 \pm 0.001$ & $5.59 \pm 5$ & $8 \pm 4$ & $89 \pm 4$ & Moderate \\
\hline PEP-5 & $350 \pm 15$ & $158.4 \pm 7$ & $0.18 \pm 0.003$ & $8.38 \pm 6$ & $13.04 \pm 7$ & $86 \pm 5$ & Moderate \\
\hline PEP-10 & $365 \pm 15$ & $160.4 \pm 6$ & $0.19 \pm 0.001$ & $9.37 \pm 5$ & $8.93 \pm 8$ & $88 \pm 5$ & Moderate \\
\hline OCT-5 & $360 \pm 10$ & $161.6 \pm 6$ & $0.21 \pm 0.002$ & $9.69 \pm 3$ & $7.90 \pm 5$ & $89 \pm 2$ & Moderate \\
\hline OCT-10 & $380 \pm 5$ & $160.8 \pm 5$ & $0.18 \pm 0.002$ & $10.42 \pm 5$ & $8.67 \pm 4$ & $84 \pm 6$ & Moderate \\
\hline DMSO-5 & $370 \pm 15$ & $162.4 \pm 8$ & $0.19 \pm 0.001$ & $9.87 \pm 6$ & $9.89 \pm 3$ & $84 \pm 4$ & Moderate \\
\hline DMSO-10 & $382 \pm 10$ & $161.2 \pm 6$ & $0.19 \pm 0.003$ & $12.57 \pm 4$ & $7.90 \pm 4$ & $87 \pm 4$ & Moderate \\
\hline
\end{tabular}

B) In-vitro evaluation of Transdermal formulations

Table: 6:- (In vitro drug permeation profile of tadalafil with various permeation enhancers)

\begin{tabular}{|l|l|l|l|l|l|l|l|l|l|l|}
\hline $\begin{array}{l}\text { Sr. } \\
\text { No }\end{array}$ & $\begin{array}{l}\text { Time } \\
\text { Hrs }\end{array}$ & \multicolumn{9}{|c|}{ Formulations } \\
\hline & & WPE & EUG-5 & EUG-10 & PEP-5 & PEP-10 & OCT-5 & OCT-10 & $\begin{array}{l}\text { DMSO- } \\
5\end{array}$ & $\begin{array}{l}\text { DMSO- } \\
10\end{array}$ \\
\hline 1 & 00 & 000 & 000 & 000 & 000 & 000 & 000 & 000 & 000 & 000 \\
\hline 2 & 2 & 8.36 & 3.50 & 3.8 & 1.69 & 6.60 & 6.60 & 9.31 & 20.82 & 24.71 \\
\hline 3 & 4 & 7.80 & 3.31 & 2.65 & 4.57 & 17.43 & 20.48 & 8.63 & 49.26 & 34.53 \\
\hline 4 & 6 & 8.02 & 4.15 & 4.18 & 5.24 & 27.42 & 20.82 & 7.28 & 41.81 & 32.16 \\
\hline 5 & 8 & 9.54 & 6.02 & 8.48 & 6.60 & 13.88 & 15.23 & 9.65 & 38.77 & 33.86 \\
\hline 6 & 10 & 13.98 & 6.80 & 14.35 & 8.97 & 21.33 & 18.45 & $\mathbf{1 3 . 5 4}$ & 46.39 & 36.72 \\
\hline 7 & 12 & 15.42 & 8.41 & 23.27 & 8.12 & $\mathbf{4 7 . 9 1}$ & 22.01 & 11.17 & 49.77 & 38.09 \\
\hline 8 & 14 & 20.06 & 8.78 & $\mathbf{2 8 . 6 8}$ & 6.60 & 23.02 & 13.54 & 5.41 & 51.63 & 37.58 \\
\hline 9 & 16 & 18.86 & 11.22 & 22.89 & 17.60 & 27.08 & 17.10 & 8.80 & 35.72 & $\mathbf{5 1 . 9 6}$ \\
\hline 10 & 18 & $\mathbf{2 3 . 5 5}$ & $\mathbf{1 4 . 0 3}$ & 18.50 & $\mathbf{2 3 . 5 3}$ & 25.56 & 16.08 & 11.17 & $\mathbf{5 9 . 4 2}$ & 40.63 \\
\hline 11 & 20 & 21.94 & 13.08 & 16.30 & 22.01 & 23.02 & 18.11 & 9.81 & 53.50 & 40.12 \\
\hline 12 & 22 & 22.97 & 12.74 & 16.72 & 17.77 & 24.38 & $\mathbf{3 4 . 7 0}$ & 10.32 & 58.74 & 47.74 \\
\hline 13 & 24 & 20.70 & 12.29 & 13.40 & 16.25 & 28.78 & 32.91 & 11.51 & 54.68 & 47.23 \\
\hline
\end{tabular}

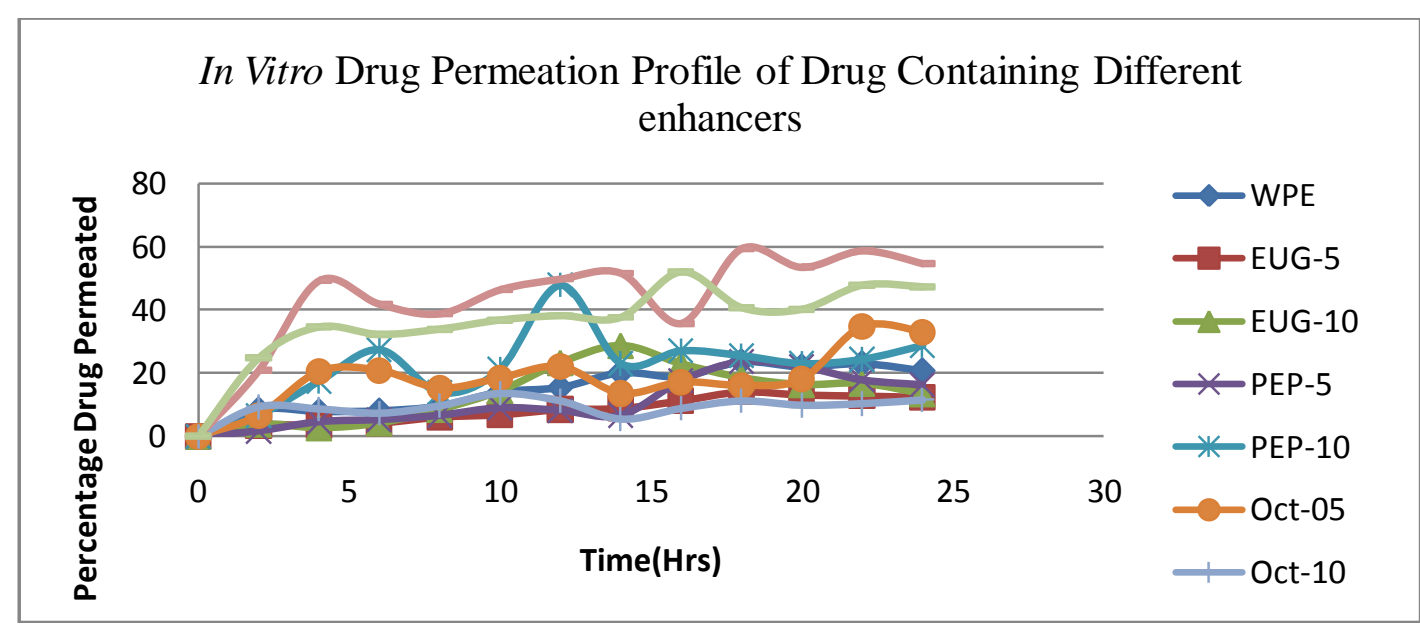

Figure 7:- (In vitro permeation studies of tadalafil with various permeation enhancers) 


\section{Discussion:-}

Prior to the formulation trials, tadalafil was characterized with regard to their solubility, UV, HPLC, FT-IR profile to confirm the purity and quality. UV confirms the absorption maxima. HPLC gives the peaks at proper retention time which tells about the purity of drug, FT-IR gives the exact peaks of functional group and it is preferred over IR because in FT-IR the sample is exposed to entire radiation beam at the same time and absorption wavelength modifies the signal. Medicated patches of tadalafil were formed using solvent casting method by using $4 \%$ w/v of chitosan as polymer and polyethylene \& glycerol (1:1) as plasticizer. Physical evaluation of formulations showed that patches formed were smooth, translucent and had uniform thickness. Patches were also evaluated for folding endurance, thickness, average weight, content uniformity, percentage moisture loss, percentage moisture gain etc. All patches were found to have good physical consistency .Table 5 showed all physical parameter of formulations being made. In vitro release studies are required for predicting the reproducibility of rate and duration of drug release.

Drug content of tadalafil in patches was found to be 84 to $89 \%$. The result showed that drug content was found to be maximum for formulation EUG-10, whereas drug content observed to be Minimum for formulation DMSO-10. The results were recorded in Table 5. This indicates minimum batch variability, which demonstrates homogenous distribution of the drug and thus, gives assurance of the strength of slow dose drugs.

Released studies are required for predicting the reproducibility of rate and duration of drug release. The importance of polymer dissolution on drug release from matrices has been known for ensuring the sustained release performance. The result showed that in vitro drug release of the Tadalafil transdermal patches was found to be Maximum for formulation WPE in $20 \mathrm{hrs}$.After 24 hours in vitro drug release observed to be minimum for formulation EUG-5 (63.74). The results are recorded in Table 4

The cumulative amount of Tadalafil permeated through rat dorsal skin, into a receptor solution, as a function of time from the various patches was observed.The result showed that in vitro drug permeation of Tadalafil transdermal patches was foundto be maximum for formulation DMSO-5(59.42) in 18 hours whereas, after 24 hours in vitro drug permeation observed to be minimum for formulation OCT-10 (13.54). The results are recorded in table 6. DMSO-5 emerging as a best formulation since it has maximum penetration through skin compare to other formulation.

Since WPE does not contain any permeation enhancer. So it has permeated only $23.56 \%$ of drug. EUG-5contain Eugenol which achieved $14.07 \%$ drug permeated. OCT-5 contain 1-Octanol which achieved $34.07 \%$ drug permeation. DMSO-5 contains Dimethyl Sulphoxide (DMSO) and achieved Maximum permeation of drug through skin $(59.42 \%)$

\section{Conclusion:-}

Controlled release TDDS patches of Tadalafil can be prepared using the polymer. Chitosan withPolyethylene glycol 400 and glycerol as plasticizer was used for formulation of TDDS. The release of drug through patches was found to be good. The drug release and permeation studies of all fabricated patches reveals that formulation DMSO-5 showed maximum release and permeation of drug for longer time period up to 24 hours. So, DMSO-5 formulation containing DMSO as penetration enhancer was suitable for development of transdermal patches to achieve maximum penetration of drug through skin compare to control patch i. e WPE formulation. Hence, proposed drug delivery system not only overcome the disadvantage of oral drug delivery but also can be exploited for the improvement of the erectile dysfunction therapy without any side effect.

\section{Acknowledgement:-}

The authors are thankful to the Ranbaxy Laboratories and Amity Institute of pharmacy, Noida for providing all facility related to research work. Atlast but not least, I amvery thankful to Almighty Allah,who gave me confidence to do my research work.

\section{Conflicts Of Interest:-}

"The author(s) declare(s) that there is no conflict of interest regarding the publication of this paper." 


\section{References:-}

1. Darwhekar G, Jain D K \&Patidar V K, Formulation and Evaluation of Transdermal Drug Delivery System of ClopidogrelBisulfate, Asian Journal of Pharmacy and Life Science,2011; 1 (3): 269.

2. Pandey S, Goyani M, Devmurari V \& Fakir J, Transferosomes: A Novel Approach for Transdermal Drug Delivery, Scholar Research Library, 2009; 1 (2): 143-150.

3. Forgue S T, Patterson B E, Bedding A W, Payne D C, Phillips D L \&Wrishko R E et al, Tadalafil pharmacokinetics in healthy subjects, British Journal of Clinical Pharmacology, 2005; 61 (3): 280-288.

4. Al Kaf A, Gouda AA, Spectrophotometric determination of tadalafil in pure and dosage forms, Chemical Industry \& Chemical Engineering Quarterly, 2010; 17 (2): 125-132.

5. Ansari K, Singhai A K, Saraogi G K \&Patil S, Transdermal Drug Delivery of Salbutamol Sulphate with Different Concentration of Polymers, International Journal of Research in Pharmacy and Science, 2011;1(3): $50-65$.

6. Garala k C, Shinde A J \&. Shah P H, Formulation and in-vitro characterization of monolithic matrix transdermal systems using HPMC/eudragit 100 polymer blends, international journal of pharmacy and pharmaceutical science, 2009; 1(1).

7. Reddy B P, Reddy K A \& Reddy M S, Validation and stability indicating RP-HPLC method for the determination of tadalafil API in pharmaceutical formulations, Research In Pharmaceutical Biotechnology, 2010; 2(1).

8. Reddy B P, Reddy K A \& Reddy M S, Validation and stability indicating RP-HPLC method for the determination of tadalafil API in pharmaceutical formulations, Research In Pharmaceutical Biotechnology, 2010; 2(1).

9. Samala A, RP-HPLC method development and validation of tadalafil in tablet dosage form ,Journal of Chemical and Pharmaceutical Research, 2013; 5(4): 315-318.

10. Aquil M, Ali A, Sultana Y \&Najmi A K, Fabrication and evaluation of polymeric films for transdermal delivery of pinacidil, Pharmazie, 2004; 59: 631-635.

11. Vijaya R, In vitro and In vivo characterization of the transdermal delivery of sertraline hydrochloride Films DARU, 2011; 19(6).

12. Yunoos M, UV spectrophotometric method for the estimation of tadalafil in bulk and tablet dosage form, EJournal of Chemistry, 2010; 7(3). 